\title{
Effect of Ionic Strength on the rate of Acetophenone-Phenylhydrazine reaction
}

\author{
*K. Nagajyothi, \#I. Ameeth Basha, \$P.S. Raghavan \\ *\#Department of Chemistry, Aarupadai Veedu Institute of Technology, Paiyanoor. \\ \$Deaprtment of Chemistry, Madras Christian College, Tambaram, Chennai
}

\begin{abstract}
The effect of ionic strength on the rate of Acetophenone-Phenylhydrazine reaction has been studied by determining the rate in the presence of added neutral salts $\mathrm{NaNO}_{3}$ and $\mathrm{NaCl}$. The kinetics were also carried out for substituted acetophenones with phenylhydrazine in the presence of $\mathrm{NaNO}_{3}$ and $\mathrm{NaCl}$. The rate constants were determined and fitted into extended LFER equation and $\rho_{I} / \rho_{R}$ were determined.
\end{abstract}

\section{Introduction}

Phenylhydrazone formation by carbonyl compounds are well known in organic chemistry and are being used to identify the functional groups. Phenylhydrazones show efficient fungicidal activity and are important intermediates in the synthesis of carbazoles, triazoles and some pesticides. Though reports are abundantly available on different methodologies of synthesizing phenylhydrazones, the kinetic details are few and far.

Structural modifications of a reactant molecule may in principle influence the rate or equilibrium constants of a reaction through polar, resonance or steric effects ${ }^{1}$. Linear free energy relationships, notably the Hammett equation, are very important tools for structure-activity correlation ${ }^{2}$.

The solvent effect ${ }^{3}$ and micellar effect ${ }^{4}$ on acetophenone-phenylhydrazine reaction have been studied.

\section{Experimental}

Phenylhydrazine and Acetophenones of AR grade (Merck) were used in all the reactions. 80\% acetic acid $-20 \%$ water solvent media was used throughout the reactions. Phenylhydrazine $[\mathrm{PH}]$ of concentration $2 \times 10^{-2} \mathrm{M}$ and substituted acetophenones [XAP] of concentration $2 \times 10^{-4} \mathrm{M}$ were prepared. Reactions were carried out at $30^{\circ} \mathrm{C}$. The kinetics of phenylhydrazine and substituted acetophenones was followed at various concentrations of $\mathrm{NaNO}_{3}$ and $\mathrm{NaCl}$ using UV-Visible spectrophotometer (Chemito 2600) at 360nm, which is the characteristic wavelength of corresponding phenylhydrazone product. The initial concentration of acetophenone was fixed at $2 \times 10^{-4} \mathrm{M}$ and a sufficient excess of nucleophilic reagent (phenylhydrazine) was employed, so that pseudo first-order rate behaviour was observed. The specific rate constants were calculated from the integrated rate equation:

$$
\mathrm{k}=\frac{2.303}{\mathrm{t}} \log \quad \frac{\mathrm{A} \alpha-\mathrm{A}_{0}}{\mathrm{~A} \alpha-\mathrm{A}_{\mathrm{t}}}
$$

Where $A_{0}$ is the absorbance of the product initially at time $(t)=0$ seconds. $A_{t}$ is the absorbance of the product at time $t$ and A $\alpha$ is the absorbance of the product at $\alpha$.

\section{Results And Discussions}

Table - 1

Rate constants $\left(\mathrm{k}_{1} \times 10^{4} \mathrm{~S}^{-1}\right)$ for the XAP-PH reaction in the presence of $\mathrm{NaNO}_{3}$

$[\mathrm{PH}]=2 \times 10^{-2} \mathrm{M}$

Solvent $=80 \%$ Acetic acid $-20 \%$ Water

$[\mathrm{XAP}]=2 \times 10^{-4} \mathrm{M}$

Temperature $=30^{\circ} \mathrm{C}$.

\begin{tabular}{|c|c|c|c|c|c|c|}
\hline $\mathrm{NaNO}_{3}$ & $p-\mathrm{OCH}_{3} \mathrm{AP}$ & $p-\mathrm{CH}_{3} \mathrm{AP}$ & $\mathrm{AP}$ & $p$-FAP & $p$-ClAP & $p$-NO \\
\hline $\mathrm{Nil}$ & 0.57 & 0.71 & 0.87 & 3.65 & 3.81 & 12.76 \\
\hline 0.01 & 2.25 & 2.23 & 2.26 & 1.36 & 1.28 & 8.18 \\
\hline 0.02 & 2.36 & 2.48 & 2.30 & 1.23 & 1.14 & 8.08 \\
\hline 0.10 & 2.47 & 2.52 & 2.42 & 1.20 & 0.89 & 7.61 \\
\hline 0.20 & 2.50 & 2.57 & 2.48 & 1.15 & 0.72 & 7.20 \\
\hline
\end{tabular}


[ $p$-OCH ${ }_{3} \mathrm{AP}$ - para methoxy acetophenone, $p-\mathrm{CH}_{3} \mathrm{AP}$ - para methyl acetophenone, parent acetophenone, $p$-FAP para-fluoro acetophenone, $p$ - $\mathrm{ClAP}$ - para chloro acetophenone, and $p-\mathrm{NO}_{2} \mathrm{AP}$ - para nitroacetophenone respectively]

The data suggests that the added $\mathrm{NaNO}_{3}$ exhibited a dual behavior - viz with increase in its concentration, increases the rate for electron donating substituents on acetophenone but resulting in a perceptible reduction in rate for reactions with electron withdrawing substituents on acetophenone. The data in Table -1 have been fitted into the extended LFER equation

$$
\log \quad \frac{\mathrm{kx}}{\mathrm{k}_{\mathrm{O}}}=\rho_{\mathrm{I}} \sigma_{\mathrm{I}}+\rho_{\mathrm{R}} \sigma_{\mathrm{R}}
$$

Where $\mathrm{kx}$ and $\mathrm{k}_{\mathrm{O}}$ are the observed rate constants for the substituted and parent acetophenone respectively, $\sigma_{\mathrm{I}} \& \sigma_{\mathrm{R}}$ are the respective substituent constants for the inductive and resonance contribution; the $\rho_{\mathrm{I}} \& \rho_{\mathrm{R}}$ are the inductive and resonance reaction constant contributions for the overall reaction.

From LFER equation, $\rho_{\mathrm{I}} \& \rho_{\mathrm{R}}$ are determined.

\section{Table -2}

$\rho_{I} \& \rho_{R}$ values for $\mathrm{XAP}-\mathrm{PH}$ reaction in the presence of $\mathrm{NaNO}_{3}$

$[\mathrm{PH}]=2 \times 10^{-2} \mathrm{M}$
$[\mathrm{XAP}]=2 \times 10^{-4} \mathrm{M}$
\begin{tabular}{|c|c|c|}
\hline $\mathrm{NaNO}_{3}$ & \multicolumn{2}{c|}{ Solvent $=80 \%$ Acetic acid $-20 \%$ Water } \\
\hline 0.00 & $\rho_{\mathrm{I}}$ & $\rho_{\mathrm{R}}$ \\
\hline 0.01 & 1.47 & 0.62 \\
\hline 0.02 & 0.42 & 0.73 \\
\hline 0.10 & 0.38 & 0.76 \\
\hline 0.20 & 0.28 & 0.81 \\
\hline & 0.24 & 0.87 \\
\hline
\end{tabular}

The trend in the $\rho_{\mathrm{I}} \& \rho_{\mathrm{R}}$ in the above table suggests that with increase in $\left[\mathrm{NaNO}_{3}\right]$, the resonance contribution of the substituent groups moderately increases while their inductive contribution suffers drastically.

The same reactions were repeated in the presence of $\mathrm{NaCl}$ and the data was subjected to LFER fit.

Table -3

$\rho_{\mathbf{I}} \& \rho_{\mathbf{R}}$ values for the $\mathrm{XAP}-\mathrm{PH}$ reaction in the presence of $\mathrm{NaCl}$

\begin{tabular}{l|c|c|}
{$[\mathrm{PH}]=2 \times 10^{-2} \mathrm{M}$} & \multicolumn{3}{c|}{ Solvent $=80 \%$ Acetic acid $-20 \%$ Water } \\
{$[\mathrm{XAP}]=2 \times 10^{-4} \mathrm{M}$} & Temperature $=30^{\circ} \mathrm{C}$. \\
\hline $\mathrm{NaCl}$ & $\rho_{\mathrm{I}}$ & $\rho_{\mathrm{R}}$ \\
\hline 0.00 & 1.47 & 0.62 \\
\hline 0.10 & 0.30 & 0.97 \\
\hline 0.20 & 0.21 & 1.00 \\
\hline
\end{tabular}

It was observed that an enhanced resonance contribution by the substituents in the presence of $\mathrm{NaCl}$ and a dramatic reduction in their inductive contribution, similar to the one observed in the presence of $\mathrm{NaNO}_{3}$.

\section{References}

[1] L.P. Hammett, Phy. Org. Chem., The Hammett's Equation, McGraw Hill, New York, Edn. 1(1940).

[2] L.P. Hammett, Phy. Org. Chem., The Hammett Equation and Chemical Reactivity, McGraw Hill,New York, edn. 2 (1970).

[3] K. Nagajyothi, P S Raghavan and R Gopalan, Solvent and Substituent Effect on

[4] Acetophenone-Phenylhydrazone Formation, Asian Journal of Chemistry, 839-842, Vol. 22, No. 2 (2010)

[5] K. Nagajyothi, P S Raghavan and R Gopalan, Micellar Effect on The Reaction of Acetophenone with Phenylhydrazine,

[6] Asian Journal of Chemistry, 829-833, Vol. 22, No. 2 (2010) 